\title{
Global investigation of estrogen-responsive genes regulating lipid metabolism in the liver of laying hens
}

\author{
Junxiao Ren ${ }^{1 \dagger}$, Weihua $\operatorname{Tian}^{1+}{ }^{1}$, Keren Jiang ${ }^{1}$, Zhang Wang ${ }^{1}$, Dandan Wang ${ }^{1,2,3}$, Zhuanjian Li, ${ }^{1,2,3}$, Fengbin Yan ${ }^{1,2,3}$, \\ Yanbin Wang ${ }^{1,2,3}$, Yadong Tian ${ }^{1,2,3}$, Kepeng Ou ${ }^{4}$, Hongjun Wang ${ }^{5}$, Xiangtao Kang ${ }^{1,2,3}$, Hong Li ${ }^{1,2,3^{*}}$ and \\ Xiaojun Liu ${ }^{1,2,3^{*}}$
}

\begin{abstract}
Background: Estrogen plays an essential role in female development and reproductive function. In chickens, estrogen is critical for lipid metabolism in the liver. The regulatory molecular network of estrogen in chicken liver is poorly understood. To identify estrogen-responsive genes and estrogen functional sites on a genome-wide scale, we determined expression profiles of mRNAs, IncRNAs, and miRNAs in estrogen-treated ((17ß-estradiol)) and control chicken livers using RNA-Sequencing (RNA-Seq) and studied the estrogen receptor a binding sites by ChIPSequencing (ChIP-Seq).

Results: We identified a total of 990 estrogen-responsive genes, including 962 protein-coding genes, 11 miRNAs, and 17 IncRNAs. Functional enrichment analyses showed that the estrogen-responsive genes were highly enriched in lipid metabolism and biological processes. Integrated analysis of the data of RNA-Seq and ChIP-Seq, identified 191 genes directly targeted by estrogen, including 185 protein-coding genes, 4 miRNAs, and 2 IncRNAs. In vivo and in vitro experiments showed that estrogen decreased the mRNA expression of PPARGC1B, which had been reported to be linked with lipid metabolism, by directly increasing the expression of miR-144-3p.

Conclusions: These results increase our understanding of the functional network of estrogen in chicken liver and also reveal aspects of the molecular mechanism of estrogen-related lipid metabolism.
\end{abstract}

Keywords: RNA-Seq, ChIP-Seq, miR-144, estrogen, Chicken, Liver

\section{Background}

Liver is the central organ of lipid metabolism, especially in chicken, where more than $90 \%$ of the de novo synthesis of fatty acids takes place [1-3]. During egg-laying periods, large amounts of triacylglycerols, cholesteryl esters, and free fatty acids are synthesized and assembled into egg-yolk precursors such as very low-density lipoprotein (VLDL) and vitellogenin (VTG) in the liver, then

\footnotetext{
*Correspondence: lihong19871202@163.com; xjliu2008@hotmail.com †Junxiao Ren and Weihua Tian contributed equally to this work. ${ }^{1}$ College of Animal Science and Veterinary Medicine, Henan Agricultural University, Zhengzhou 450002, China

Full list of author information is available at the end of the article
}

secreted into the blood stream, transported to the ovary and taken up by the growing oocytes [4]. Our previous RNA-Seq analysis on the liver of pre-laying (20 weeks old) and peak-laying chickens (30 weeks old) identified 960 differentially expressed (DE) genes including mRNA and non-coding RNA genes, many of which have been shown to participate in lipid metabolism pathways $[5,6]$. Hence, the active lipid related genes in liver plays an important role in adaption of the physiological changes from pre-laying to peak-laying stages in hens.

The physiological processes of lipid metabolism in chicken liver are tightly regulated by estrogen at the egg-

(c) The Author(s). 2021 Open Access This article is licensed under a Creative Commons Attribution 4.0 International License, which permits use, sharing, adaptation, distribution and reproduction in any medium or format, as long as you give appropriate credit to the original author(s) and the source, provide a link to the Creative Commons licence, and indicate if changes were made. The images or other third party material in this article are included in the article's Creative Commons licence, unless indicated otherwise in a credit line to the material. If material is not included in the article's Creative Commons licence and your intended use is not permitted by statutory regulation or exceeds the permitted use, you will need to obtain permission directly from the copyright holder. To view a copy of this licence, visit http://creativecommons.org/licenses/by/4.0/ The Creative Commons Public Domain Dedication waiver (http://creativecommons.org/publicdomain/zero/1.0/) applies to the data made available in this article, unless otherwise stated in a credit line to the data. 
laying cycle $[7,8]$. Estrogen exerts essential physiological functions mainly through the two known nuclear estrogen receptor (ER) subtypes ER $\alpha$ and ER $\beta$, which directly bind to the consensus estrogen response elements (EREs) $[9,10]$ or indirectly bind to nuclear DNA by interacting with other DNA-bound transcription factors such as Ap1and SP1 [11, 12] to regulate transcription of their target genes. In addition, estrogen can also specifically bind to the $G$ protein-coupled receptor GPER (known as GPR30) and activate the intracellular signaling cascade [13]. All of the receptors may synergistically or antagonistically mediate multiple physiological and pathological processes by the interaction of all activation and inhibition pathways [14]. To further understand the molecular mechanism underlying the complex interactions among transduction pathways in response to estrogens, global maps of ER binding sites and target genes in the whole genome were obtained in various cell types and tissues by employing chromatin immunoprecipitation (ChIP)-based assays [9, 15, 16]. However, only some classic estrogen target genes such as apolipoprotein $\mathrm{B}$ (APOB) and apovitellenin 1 (APOV1) are reported to be regulated by estrogen in chicken $[17,18]$. Therefore, systematic study on the estrogen-responsive genes including mRNAs and noncoding RNAs is necessary for revealing the regulatory mechanism of lipid metabolism in chicken liver.

In this study, RNA-seq was performed to investigate the expression profiles of mRNAs, IncRNAs, and miRNAs in livers of estrogen-stimulated and control juvenile hens. ChIP-Seq of ER $\alpha$ was conducted to map estrogen receptor binding sites in liver. Integrative analysis of the above RNA-seq data and ChIP-seq data was carried out to explore the genome-wide estrogen-responsive genes involved in lipid metabolism mediated via $\mathrm{ER} \alpha$ in the chicken liver. One of the estrogen-mediated lipid metabolic pathways regulated by miR-144 was proven. The results provide a genome-wide comprehensive expression profile of mRNAs and noncoding RNAs directly regulated by estrogen via ER $\alpha$-binding sites and the estrogen-regulated network of lipid metabolism in chicken liver.

\section{Results}

Effects of estrogen on lipid metabolism in chicken liver

To verify whether exogenous estrogen had a biological role in chicken, the mRNA expression levels of the two classic target genes of estrogen, $A P O B$ and $A P O V 1$, were detected in liver tissue. The expression of APOB mRNA was significantly increased 80 -fold, and APOV1
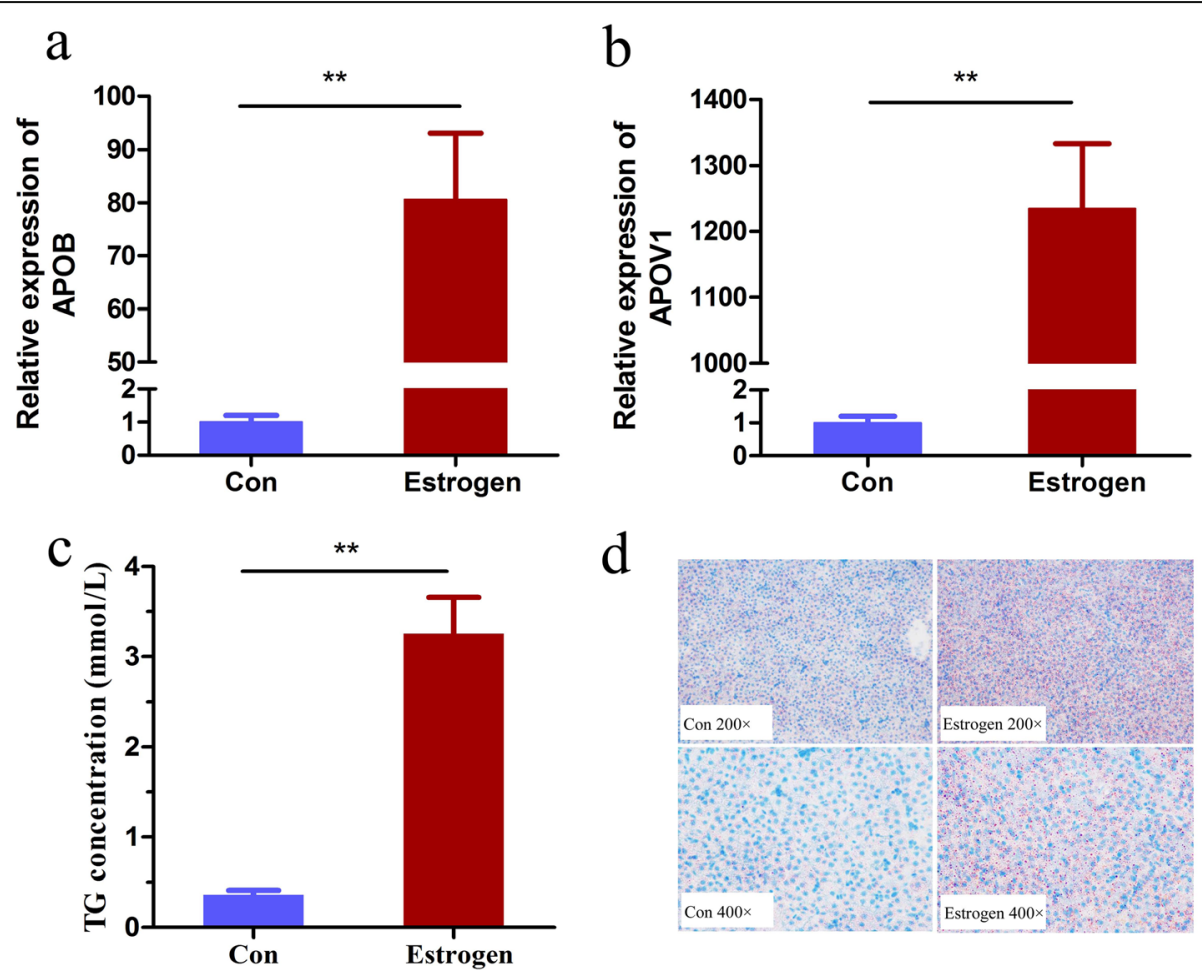

Fig. 1 Effect of 17ß-estradiol on lipid metabolism in chicken. a qRT-PCR analysis of liver APOB mRNA induction in response to 17ß-estradiol. $\mathbf{b}$ qRT-PCR analysis of liver APOV1 mRNA induction in response to 17ß-estradiol. c Assessment of plasma TG upregulation in response to 17 $\beta$ estradiol. d A liver tissue section stained with oil red $O$ and hematoxylin. All error bars represent SEM, $n=6$ for the control group and $n=8$ for the $17 \beta$-estradiol treatment group, ${ }^{* *} p<0.01$. Chicken injected with $17 \beta$-estradiol at $8.0 \mathrm{mg} / \mathrm{kg}$ of body weight were used in this part 
increased 1250-fold in the estrogen stimulated group compared to the control group (Fig. 1a, b). This indicated that estrogen administration was effective. The triglyceride (TG) content in the serum was significantly increased after estrogen treatment $(P<0.05)$ (Fig. 1c). The result of oil red $\mathrm{O}$ staining of liver tissue showed more lipid droplets in the liver of estrogen-treated chicken than in the controls (Fig. 1d). These data suggest that estrogen stimulation can significantly promote lipid synthesis and transport in the chicken liver.

\section{Identification of estrogen-responsive mRNA and ncRNA in chicken liver}

To identify the estrogen-responsive protein-coding genes and lncRNA genes in liver, RNA-Seq of livers from chickens treated with $17 \beta$-estradiol and the control groups was performed. An overview of the RNA-Seq data is presented in Table S1. After assembly, a total of 15,556 protein-coding genes were identified. Among them, 540 genes were significantly upregulated and 422 were significantly downregulated ( $\mid \log _{2}$ fold change $\mid \geq 1$ and false discovery rate $(F D R) \leq 0.05$; Fig. 2a; Table S2), including some known estrogen target genes, such as APOB, APOV1, PPARG, LPL, and THRSP [17, 19, 20]. The top five genes with the largest changes in the mRNA level were ENSGALG00000020772 (uncharacterized protein), ENSGALG00000012204 (uncharacterized protein), ENSGALG00000001863 (VTG2), ENSGALG00000015134 (APOV1), and ENSGALG00000008900 (VTG1). A total of 4144 known lncRNAs and 1598 novel lncRNAs were identified. Among them, seven lncRNAs were significantly upregulated and $10 \operatorname{lncRNAs}$ were significantly downregulated ( $\left|\log _{2}{ }^{\text {fold change }}\right| \geq 1$ and FDR $\leq 0.05$; Fig. 2b; Table S2).

To identify the estrogen-responsive miRNA genes, miRNA-Seq of the livers from the $17 \beta$-estradiol treated and the control chickens was performed. A total of 23.08 million reads per sample were generated (Table
S3). In total, 575 known miRNAs and 153 novel miRNAs were identified. Among them, five miRNAs were significantly upregulated and six were significantly downregulated (fold change $\geq 1.5$, and FDR $\leq 0.05$; Fig. 2c; Table S2).

\section{Functional annotation of estrogen-responsive mRNA and ncRNA}

To study the functions of the differentially expressed estrogen-responsive genes, Gene Ontology (GO) and Kyoto Encyclopedia of Genes and Genomes (KEGG) pathway enrichment analyses were performed. The GO enrichment analysis showed that the set of $\mathrm{DE}$ genes was significantly enriched in $59 \mathrm{GO}$ terms. Among them, 17 (28.8\%) GO terms were lipid-related (Table 1), including lipid localization (GO: 0010876), fatty acid metabolic process (GO: 0006631), lipid biosynthetic process (GO: 0008610), and lipid transport (GO: 0006869). KEGG pathway enrichment analysis indicated that the set of DE genes was significantly enriched in 14 KEGG pathways. Seven (50\%) KEGG pathways were lipidrelated (Table 2), which included fatty acid metabolism (gga01212), fatty acid degradation (gga00071), fatty acid biosynthesis (gga00061), and the PPAR signaling pathway (gga03320).

To assess the possible participation of miRNAs in lipid metabolism, the potential target genes of the 10 estrogenresponsive miRNAs were predicted by means of miRDB, TargetScan, and PicTar. There were 122 high-scoring potential miRNA-mRNA pairs among the 11 estrogenresponsive miRNA genes and 109 differentially expressed estrogen-responsive protein-coding genes. A network of the differential expressed miRNAs and predicted target genes was constructed using Cytoscape (Fig. 3). Function annotation of the 109 potential target genes showed that the gene set was significantly enriched in lipid-related terms, including lipid biosynthetic process $(p=1.47 \mathrm{E}-05)$,
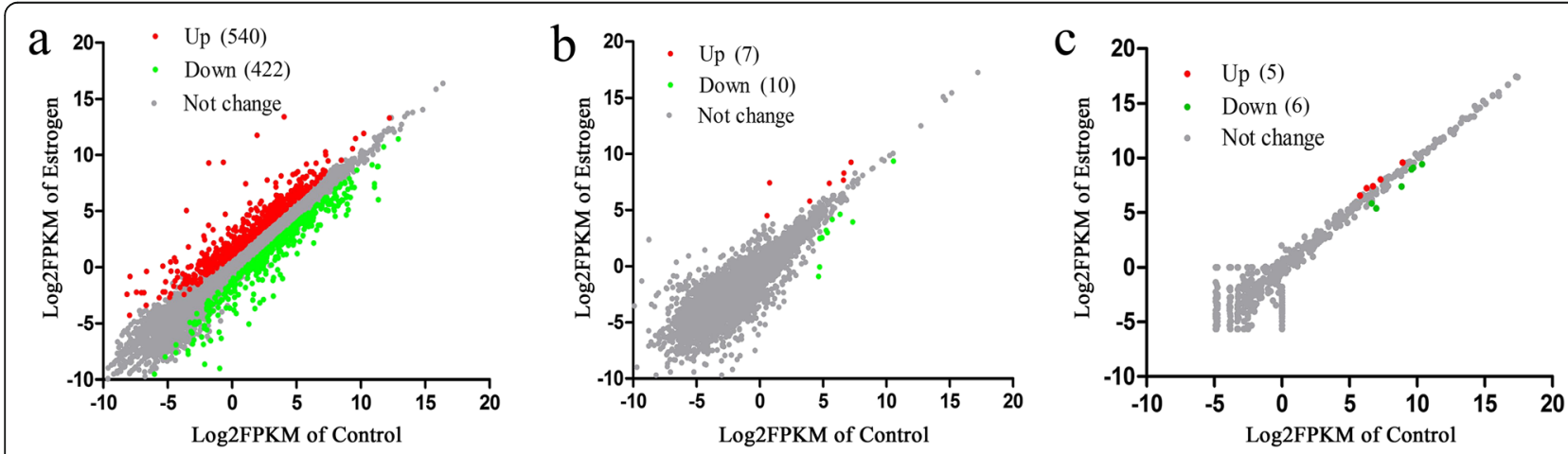

Fig. 2 RNA-Seq data analyses. a, b The $\log _{2}{ }^{\text {FPKM }}$ scatter plot depicting changes in the expression of protein-coding mRNAs (a) and IncRNAs (b) detected by RNA-Seq. Transcripts with $\log _{2}$ fold change $\leq-1$ are shown in green, with a $\log _{2}$ fold change $\geq 1$ in red, and with $1>\log _{2}$ fold change $>-1$ in gray. $\mathbf{c}$ The $\log _{2}{ }^{\text {TPM }}$ scatter plot depicting expression changes of miRNAs detected by miRNA-Seq. Transcripts with fold change $\leq 0.667$ are green, those with fold change $\geq 1.5$ are red, and others are gray 
Table 1 The GO terms correlated to lipid metabolism

\begin{tabular}{|c|c|c|c|c|}
\hline GO_ID & GO_term & Number of DE genes & Fold Enrichment & $q$-value \\
\hline GO:0006629 & lipid metabolic process & 94 & 2.155 & 0.000 \\
\hline GO:0006631 & fatty acid metabolic process & 32 & 3.514 & 0.000 \\
\hline GO:0010876 & lipid localization & 29 & 2.899 & 0.001 \\
\hline GO:0055088 & lipid homeostasis & 15 & 4.773 & 0.001 \\
\hline GO:0008610 & lipid biosynthetic process & 46 & 2.234 & 0.001 \\
\hline GO:0006869 & lipid transport & 24 & 2.772 & 0.006 \\
\hline GO:0019395 & fatty acid oxidation & 11 & 4.288 & 0.015 \\
\hline GO:0016125 & sterol metabolic process & 12 & 3.742 & 0.020 \\
\hline GO:0016126 & sterol biosynthetic process & 7 & 6.420 & 0.021 \\
\hline GO:0034440 & lipid oxidation & 11 & 4.084 & 0.021 \\
\hline GO:0006639 & acylglycerol metabolic process & 11 & 3.898 & 0.023 \\
\hline GO:0006638 & neutral lipid metabolic process & 11 & 3.811 & 0.027 \\
\hline GO:0016042 & lipid catabolic process & 20 & 2.515 & 0.033 \\
\hline GO:0046464 & acylglycerol catabolic process & 5 & 7.796 & 0.041 \\
\hline GO:0050994 & regulLation of lipid catabolic process & 7 & 5.197 & 0.042 \\
\hline GO:0006633 & fatty acid biosynthetic process & 13 & 3.118 & 0.043 \\
\hline GO:0010883 & regulLation of lipid storage & 7 & 4.961 & 0.049 \\
\hline
\end{tabular}

Fold Enrichment: fold enrichment = GeneRatio $/$ BgRatio, the results were obtained by David tool

fatty acid metabolism pathway ( $p=3.45 \mathrm{E}-05)$, and PPAR signaling pathway $(p=0.0001)$. These estrogen-responsive miRNA genes might be involved in hepatic lipid metabolism.

\section{Genome-wide identification of ERa binding sites}

To determine the estrogen-responsive mRNAs mediated via ER $\alpha$ binding sites, ChIP-Seq was conducted and a data summary is given in Table S4. A total of 7000 unique ER $\alpha$ binding sites were identified. We found that a low proportion $(17.7 \%)$ of the binding sites were located $<10 \mathrm{~kb}$ upstream of the annotated TSS of genes (Fig. 4a), while $41.4 \%$ of the binding sites were located downstream of the annotated TSS of genes (Fig. 4a). All of the identified binding sites were used to perform an unbiased search for enriched motifs using MEME. The most significantly enriched motif was FOXP1 ( $p=5.6 \mathrm{e}-$ 44) (Fig. 4b). FIMO was then used to identify ERE sequences in the identified binding sites. The count matrix motif of ERE was obtained from the JASPAR database (ID: MA0112.1). This analysis was performed with stringent criteria for ERE detection. The count matrix motif of an ERE was used, with a $p$ value of $<0.0005$ and a maximum of four mismatched residues allowed within the core $15 \mathrm{bp}$ consensus ERE sequence (AGGT CAnnnTGACCT). Out of the 7000 unique ER $\alpha$ binding sites, 6492 putative EREs were identified (Fig. 4c). Only $3813(54.5 \%)$ of the binding sites occupy the putative EREs. Approximately $47 \%$ of the ER $\alpha$ binding sites do not occupy any discernable EREs. A total of $42.7 \%$ of the binding sites that occupied ERE were more than one putative ERE (Fig. 4c). All of the identified ERE sequences

Table 2 The KEGG pathways correlated to lipid metabolism

\begin{tabular}{|c|c|c|c|}
\hline Pathway ID & Pathway name & Different genes & $q$-value \\
\hline gga03320 & PPAR signaling pathway & $\begin{array}{l}\text { ACSBG2, FADS2, ACAA1, CPT1A, SCD, DBI, PLIN2, PPAR, FABP4, ACOX1, PLIN1, } \\
\text { CYPTA1, ACSL1, PEPCK, LPL, EHHADH, LFABP, FABP3 }\end{array}$ & 4.88E-06 \\
\hline gga01212 & Fatty acid metabolism & $\begin{array}{l}\text { ACSBG2, FADS2, ACACA, ACAA1, CPT1A, SCD, ACAT2, ACOX1, FADS1, FASN, } \\
\text { ELOVL2, ACSL1, ELOVL5, EHHADH, HSD17B12 }\end{array}$ & 2.09E-05 \\
\hline gga00100 & Steroid biosynthesis & HSD17B7, FDFT1, DHCR24, LSS, SQLE, NSDHL, MSMO1, CYP51A1, DHCR7 & 0.00013 \\
\hline gga01040 & Biosynthesis of unsaturated fatty acids & FADS2, ACAA1, SCD, ACOX1, FADS1, ELOVL2, ELOVL5, HSD17B12 & 0.00232 \\
\hline gga00071 & Fatty acid degradation & ACSBG2, ACAA1, CPT1A, ECI2, ALDH3A2, ACAT2, ACOX1, ACSL1, EHHADH & 0.00328 \\
\hline gga00564 & Glycerophospholipid metabolism & $\begin{array}{l}\text { PISD, ETNPPL, LPIN2, AGPAT4, PEMT, CHKA, GPAM, GNPAT, LYPLA1, AGPAT2, } \\
\text { AGPAT9, LCAT, ETNK2, PHOSPHO1, MBOAT2 }\end{array}$ & 0.00569 \\
\hline gga00061 & Fatty acid biosynthesis & $A C S B G 2, A C A C A, F A S N, A C S L 1$ & 0.01620 \\
\hline
\end{tabular}



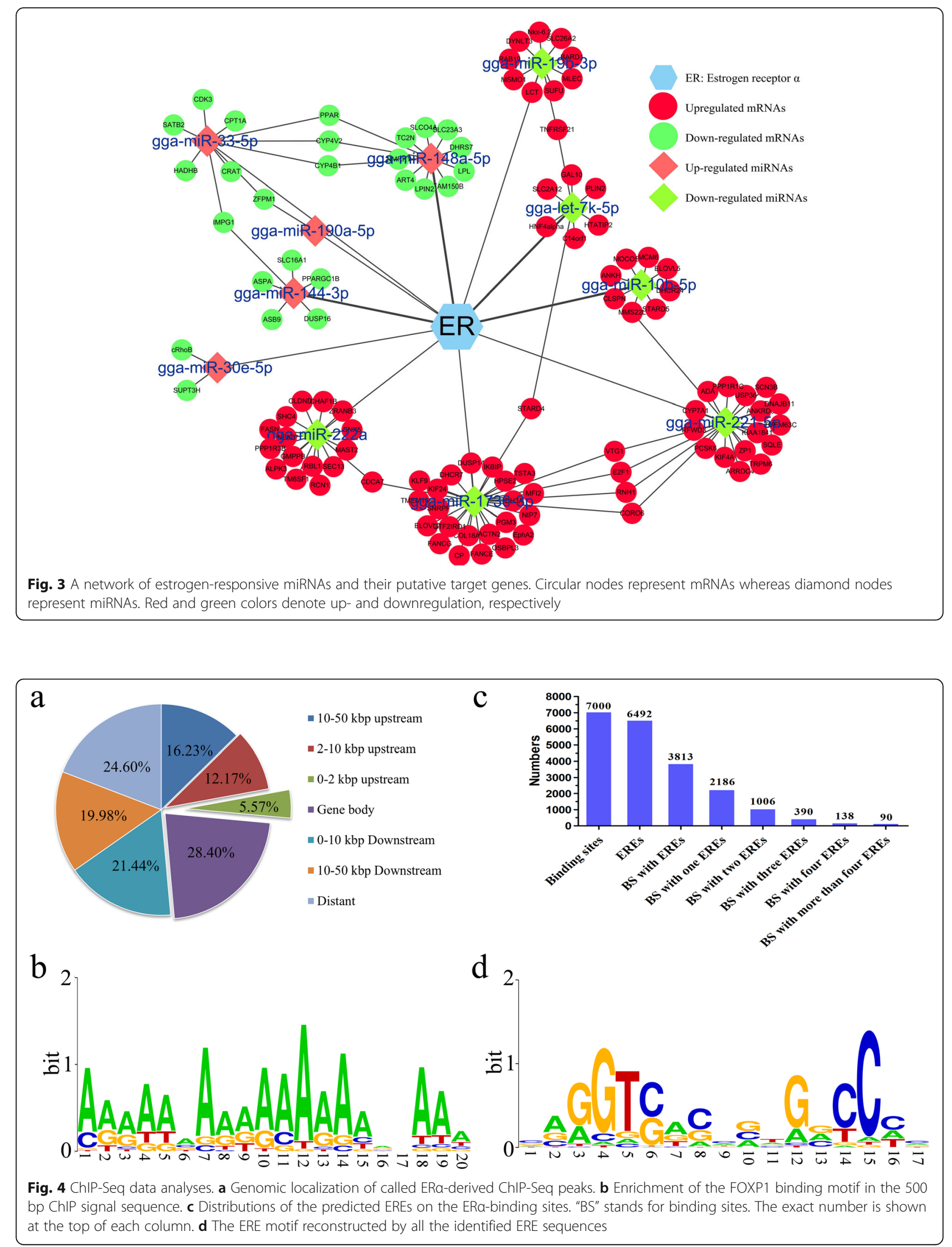
were analyzed and a count matrix motif of an ERE was reconstructed (Fig. 4d). Notably, the trinucleotide spacer sequence NNN located in the middle of the ERE seems to be preferentially in the form of CNG. These findings suggest that the presence of a consensus ERE is not necessary for the binding of ER $\alpha$ to DNA in the chicken.

\section{Identification, functional analysis, and validation of the estrogen-responsive genes directly targeted by ERa via EREs}

Estrogen-responsive genes that contain ER-binding sites $<50 \mathrm{~kb}$ upstream of a TSS were considered to be direct targets of estrogen. A total of 113 genes $(11.5 \%$ of all estrogen-responsive genes) directly targeted by ER $\alpha$ via binding with EREs were identified (Table S5). Among those, four genes were miRNA, and the others were protein-coding genes. Eight genes among the 113 putative estrogen direct target genes were selected to perform qRT-PCR and ChIP-qPCR validation, including four randomly selected protein-coding genes DUSP4, PLPPR5, PEPCK1, and ECI2, two randomly selected miRNAs $m i R-144-3 p$ and miR-148a, and two known classic estrogen target genes VTG2 and APOV1. Our results proved that the expression of eight genes was significantly altered by estrogen $(P<0.05)$, and consistent with the RNA-Seq results (Fig. 5a, b, d and e). The ChIP-qPCR results showed that all eight binding sites were identified effectively (Fig. 5c, f).

\section{Estrogen suppresses PPARGC1B and DUSP16 expression by promoting miR-144-3p}

To confirm the reliability of the analysis results, the relationships among estrogen, gga-miR-144-3p, and the potential target genes PPARGC1B and DUSP16 were verified. The three predicted binding sites of $m i R-144-3 p$ in PPARGC1B and DUSP16 3'-UTR are shown in Fig. 6a, b. A dual-luciferase assay determined that $m i R-$ $144-3 p$ interacted with the site nucleotide positions $467-$ 473 nt located in the 3'UTR of PPARGC1B and the site 1923-1929 nt located in the 3'UTR of DUSP16 (Fig. 6ce). Then, the miR-144-3p mimic and inhibitor were transfected into the chicken primary hepatocytes. The results indicated that overexpression of $m i R-144-3 p$ could significantly suppress the mRNA expression of PPARGC1B and DUSP16 $(P<0.05)$ (Fig. 6f), whereas knockdown of miR-144-3p significantly increased the mRNA expression of PPARGC1B and DUSP16 $(P<0.05)$ (Fig. 6g). The 17 $\beta$-estrogen treatments significantly downregulated PPARGC1B and DUSP16 in chicken livers but upregulated miR-144-3p $(P<0.05)$ (Fig. 6h, i). Another data suggested a similar changing tend between the miR-144-3p expression and the egg production records of 2000 Lushi green-shelled-egg chickens (Fig. 6j). Moreover, the expression levels between miR-144-3p and PPARGC1B, DUSP16 in the liver of chickens at different developmental stages presented a negative correlation (Fig. 6k, l). These findings indicate that estrogen suppresses the expression of PPARGC1B and DUSP16 by promoting the expression of $m i R-144-3 p$ in the chicken liver.

\section{Discussion Lipid metabolism in chicken liver is affected by estrogen level}

Estrogen can strongly affect lipid metabolism in the liver and adipose tissue of mammals [1, 3]. We found 962 differentially expressed estrogen-responsive protein coding genes and 10 estrogen-responsive miRNAs were identified in the livers of $17 \beta$-estradiol treated hens. These included some known estrogen target genes and some novel estrogen-responsive genes, which are reported for the first time, e.g., ENSGALG00000020772, ENSG ALG00000012204, and ENSGALG0000002409. Functional analysis showed that the set of estrogenresponsive genes, including the predicted target genes of miRNAs, were significantly enriched in steroid metabolism, steroid biosynthesis, lipid metabolism, lipid localization, and PPAR signaling. We also found, using miRNA-Seq analysis, that miR-148a, which is linked to lipid metabolism [21, 22], was one of the most abundant miRNAs in the chicken liver. Several other differentially expressed known miRNAs participate in lipid metabolism, including miR33 [23], miR-10b [24], and miR-30e [25]. We previously reported a transcriptome profile of the liver of pre-laying and peak-laying chickens [6]. During the laying stage, the expression of lipid-related genes was highly stimulated in the liver to support the metabolic demands associated with reproductive organ development. Thus, most of the DEGs were considered to be lipid-related. GO and KEGG enrichment results demonstrated that DEGs were significantly enriched in lipid metabolism-related processes. We found that $33 \%$ of these genes are estrogen-responsive genes. The plasma estrogen level in female chickens reaches its peak before the onset of production of the first egg $[7,8]$, then drops gradually, but remains at a higher level than that in immature pullets [8]. Thus, we suggest that some liver DE genes between pre-laying and peak-laying chickens are estrogen inducible. The TG content in the serum of chickens was significantly increased after estrogen treatment, and the oil red $\mathrm{O}$ staining of liver tissue showed more lipid droplets in the livers of estrogen-treated chickens than in livers of the control group. Some estrogen-responsive genes are regulated during the laying period because of the increased plasma estrogen level, and they therefore participate in liver lipid metabolism. These findings provide details on the 


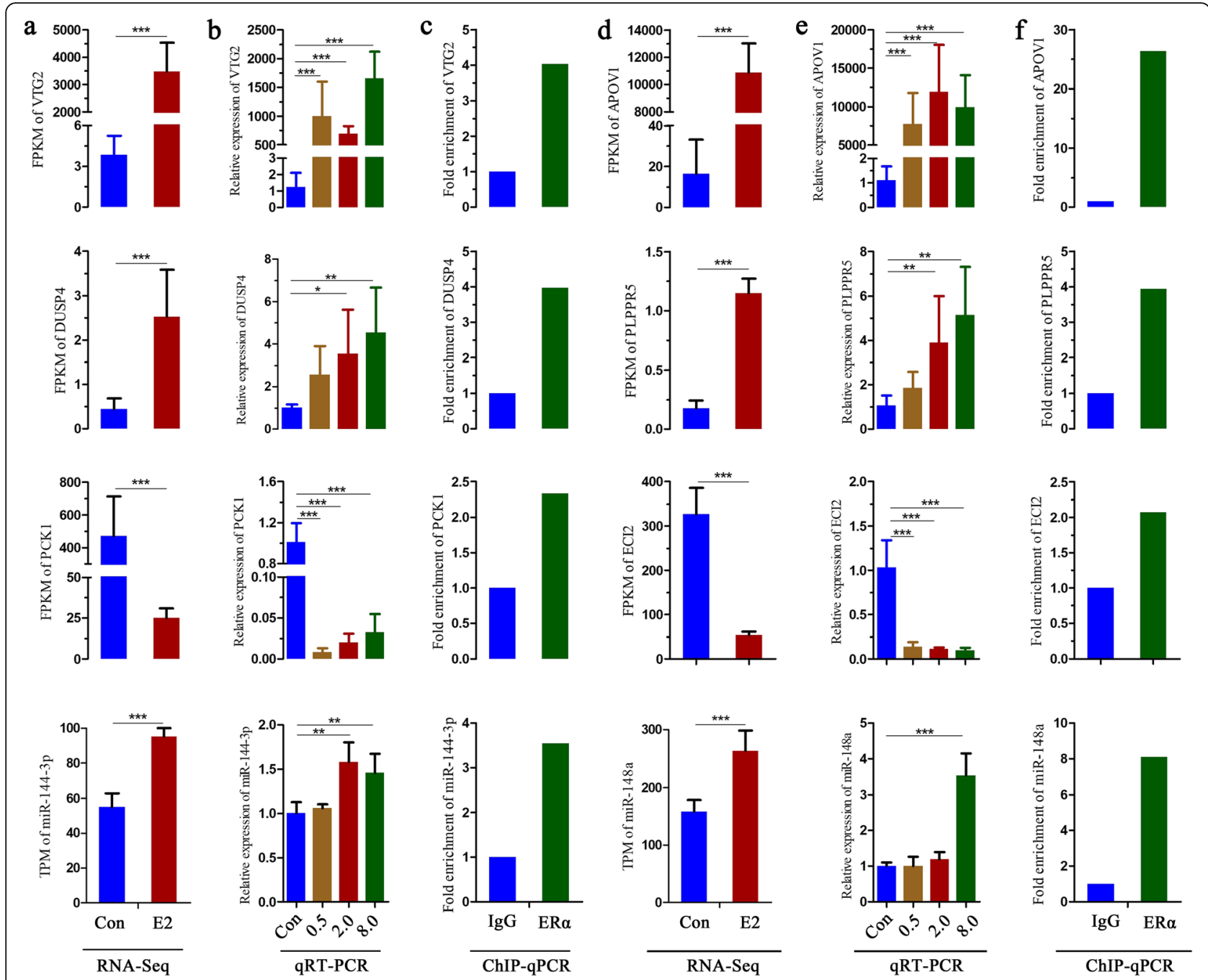

Fig. 5 Confirmation of the identified genes directly targeted by estrogen. $\mathbf{a}$, $\mathbf{d}$ FPKM/TPM data of the genes detected by RNA-Seq. $\mathbf{b}$, e Effects of $17 \beta$-estradiol on the mRNA expression of the genes detected by qRT-PCR. Error bars represent SEM, $n=6$ for the control group and $n=8$ for the $17 \beta$-estradiol treatment groups, ${ }^{*} p$ value $<0.05,{ }^{* *} p$ value $<0.01,{ }^{* * *} p$ value $<0.001$. c, f Gene-specific ChIP-qPCR analysis. Chromatin was immunoenriched with an antibody to ERa or a control lgG

regulation of lipid metabolism by estrogen signaling in the chicken liver.

\section{Location relationships between ERa binding sites and estrogen-responsive genes}

Estrogen exerts physiological functions mainly via the ER $\alpha$ and ER $\beta$, which directly bind to the consensus EREs or indirectly bind to nuclear DNA by interacting with other transcription factors to regulate gene expression [9-11]. ER $\alpha$ is mainly expressed in the female reproductive system, liver, kidney, white adipose tissue and bone, while ER $\beta$ is expressed in ovary, lung, and other tissues [26]. In laying hens, more than $90 \%$ of de novo fatty acid synthesis occurs in the liver, rather than adipose tissue, kidneys, or the gastrointestinal tract. Therefore, the chicken liver is one of the best models to study lipid metabolism. In this study, a total of $7000 \mathrm{ER} \alpha$ binding sites and 113 of the 962 estrogen-responsive genes directly targeted by estrogen via ER $\alpha$ binding to the special ERE sequence were identified in the chicken genome by ChIP-Seq. Unexpectedly, most of the identified binding sites were located away from the annotated TSS and only a small proportion $(\sim 5 \%)$ of the binding sites were located $<2 \mathrm{~kb}$ upstream of a TSS. Similar results in humans have been reported [16, 27]. Furthermore, more than $60 \%$ of the binding sites were located in the gene body and downstream of genes. However, considering that many genes occupy alternative TSS, the binding sites that were located at a gene body may also be located at the promoter of one of the gene's transcript isoforms. We do not clearly understand the induction/ suppression of the transcription of genes by ER $\alpha$, but 


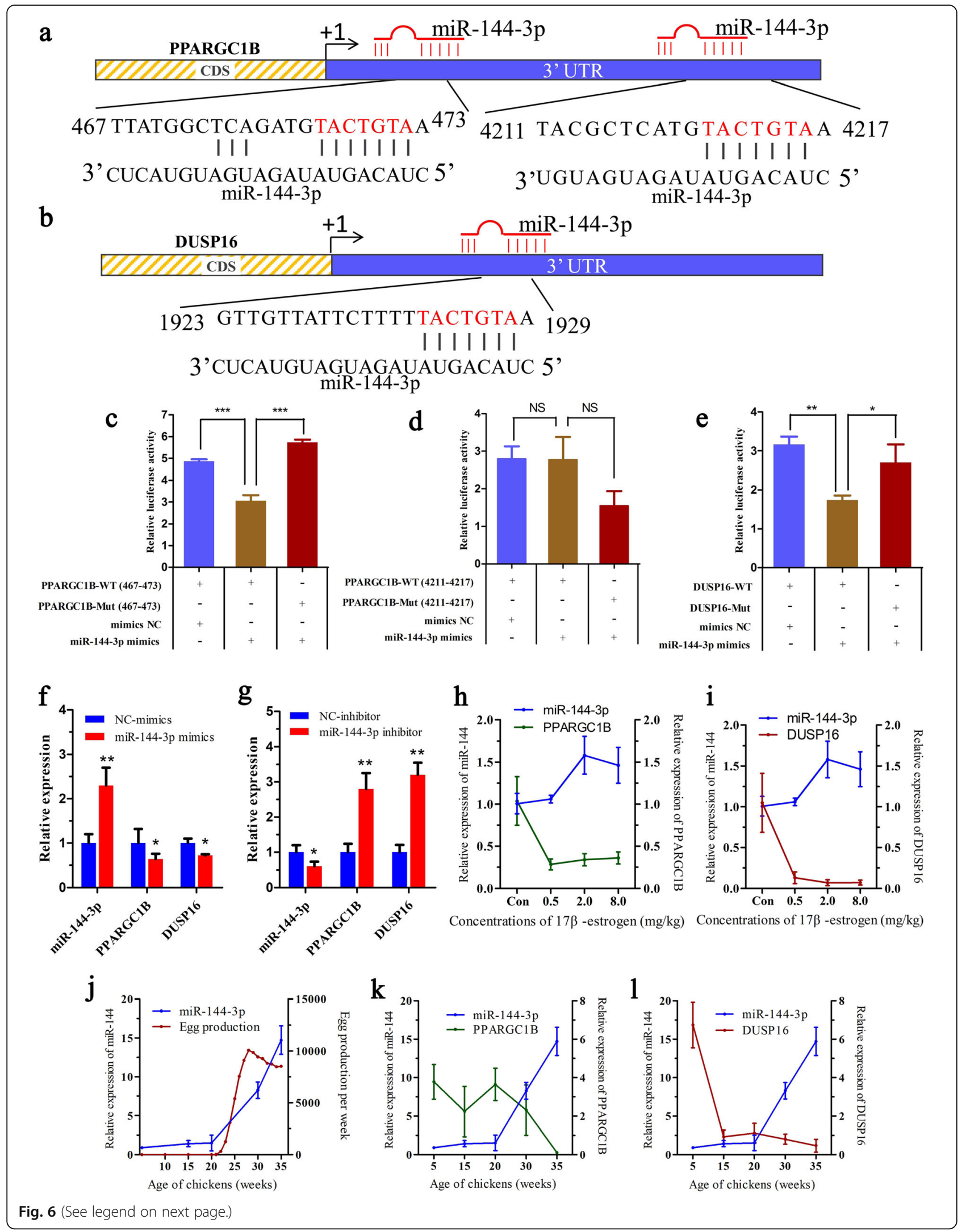




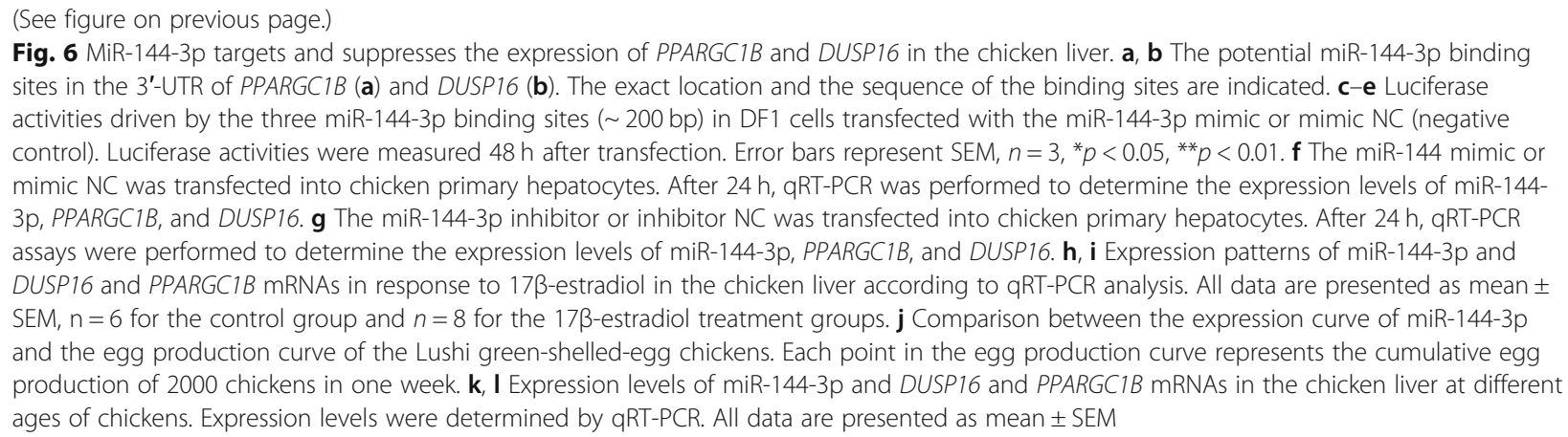

our observations suggest the existence of long-range interactions between ER $\alpha$ binding sites and the regulated promoters. Our study revealed that approximately $50 \%$ of all ER $\alpha$ binding sites do not occupy a typical ERE or discernable ERE. A similar result was reported by Mason [28]. One reason for the absence of ERE sequences at many ER $\alpha$ binding sites is that ER $\alpha$ coupled with alternative transcription factors and thus bound to DNA targets via other transcription factors motifs. For example, the well demonstrated ER-FOXA1 complexes and ER-sp1 [11, 12, 29]. Therefore, understanding the cooperating factors associated with estrogen receptors will help uncover the relationship between the estrogen receptor and its responsive genes.

\section{Estrogen receptors interact with several cooperating factors}

Estrogen regulates gene expression by two signaling pathways through ER $\alpha$ and ER $\beta$. The canonical model for ER-mediated regulation of gene expression involves the direct binding of dimeric ER to EREs. In addition, ER can indirectly associate with promoters through protein-protein interactions with other DNA-binding transcription factors. A motif analysis for ER $\alpha$ binding sites throughout the human and mouse genomes revealed that other transcription factors generally cooperate with ER $\alpha$ and modulate estrogen receptor functions. For example, FoxA1 [15, 30], FOXP1 [29], and AP1 [16] are important regulatory factors. In the present study, FOXP1 was identified as the highest-confidence motif in extended ER $\alpha$ binding sites. Together with the high similarity between the identified ERE sequence and the ERE sequence reported in mammals, our findings suggest that the avian estrogen signaling pathway is similar to that of mammals. Although numerous interacting molecules at the genome scale were identified, high resolution of the complexes at one specific genomic locus remains lacking. Liu et al. described a CRISPR affinity CAPTURE approach to identify locus-specific chromatin-regulating protein complexes without bias [31]. Their method could be helpful for identifying the interacting molecules at specific ERE loci. It was also reported that, if signaling from ER-dependent AP1 elements occurs in estrogen target tissues, ER $\alpha$ and ER $\beta$ would respond differently to ligands at AP1 sites. This reveals a potential control mechanism for the transcriptional regulation of estrogen-responsive genes [9]. Together with the various cooperating factors enriched on $E R \alpha$ binding sites, estrogen is less dependent on ER, and ER is less dependent on an ERE than previously thought. However, ER $\alpha$ occurs in a ligand-independent manner.

\section{Non-coding RNAs involved in estrogen regulation network}

Previous studies have focused on estrogen-responsive protein-coding genes. However, noncoding genes can have a variety of functions, especially the posttranscriptional regulation of gene expression or guidance of RNA modifications [32, 33]. Several studies have reported the expression profiles of miRNAs and lncRNAs after the administration of estrogen. A study on the estrogen-mediated miRNA expression profiles during cardiomyocyte hypertrophy demonstrated that estrogen can alter miRNA expression to inhibit cardiomyocyte hypertrophy [34]. Another study uncovered $34 \mathrm{DE}$ miRNAs after 6 and 12 weeks of estrogen exposure, but only 6 differentially expressed miRNAs after 18 weeks of estrogen exposure [35]. A cohort of estrogen-responsive lncRNAs was identified using estrogen receptor-positive and -negative breast tumors [36]. These studies focused on the genes manifesting differential expression after estrogen administration, but the group of noncoding genes directly or indirectly regulated by estrogen has not been studied. We focused on the genome-wide identification of noncoding RNAs whose expression is directly and indirectly regulated by estrogen. Four noncoding genes were likely to be directly targeted by estrogen. The number of estrogen-responsive noncoding genes appears much lower than that of protein-coding genes. Nevertheless, because a single noncoding RNA can target multiple protein-coding genes [37], it is possible that these noncoding genes can participate in the estrogen 
signaling pathway at a genome-wide scale. One of the estrogen-responsive miRNAs, miR-148a, can target more than 10 genes, such as MSK1 [38] and P27 [39]. Hundreds of estrogen-responsive genes were demonstrated to be putative target genes of these estrogen-responsive miRNAs. These results increase our understanding of the non-coding RNA mediated estrogen regulation network in the liver of chickens.

\section{miR-144 mediated lipid metabolism regulation by estrogen}

Both miR-144 and PPARGC1B are reported to play important roles in lipid metabolism and The miR-144 is regulated by estrogen [40]. However, no detailed network has been constructed to describe miR-144mediated lipid metabolism. In this study, we demonstrated that the $m i R-144-3 p$ gene is directly targeted by estrogen via ER $\alpha$. The upregulated $m i R-144-3 p$ suppresses the expression of its target gene PPARGC1B by binding to the 3'UTR of PPARGC1B mRNA. Downregulation of $P P A R G C 1 B$ therefore changes the lipid metabolism in the chicken liver (Fig. 7). We previously demonstrated that estrogen could repress the expression of $g g a-m i R-221-5 p$ and increase the expression of targets ELOVL6 and SQLE to promote lipid synthesis in chicken liver [41]. Thus, identification of noncoding genes targeted by estrogen is helpful for understanding the mechanism of the estrogen signaling pathway.

\section{Conclusions}

In conclusion, our integrated analysis of RNA-Seq data and ChIP-Seq data identified estrogen receptor functional sites in the chicken genome and all of the genes, including protein-coding genes, miRNAs and lncRNAs, regulated via estrogen in the liver of chicken (Fig. 7). We also demonstrated the functional role of estrogenresponsive genes in lipid metabolism. Estrogen directly targeted $m i R-144-3 p$ mediated lipid metabolism by suppressing the PPARGC1B expression level (Fig. 7). These results increase our understanding of the functional network regulated by estrogen in liver of chicken and provide insight into estrogen mediated lipid metabolism.

\section{Methods}

Animals and sampling

All animals used in the experiments were female Lushi blue-shell-egg chickens obtained from the Animal Center of Henan Agricultural University. The chickens were housed in cages separately under the same environmental conditions with ad libitum access to food and

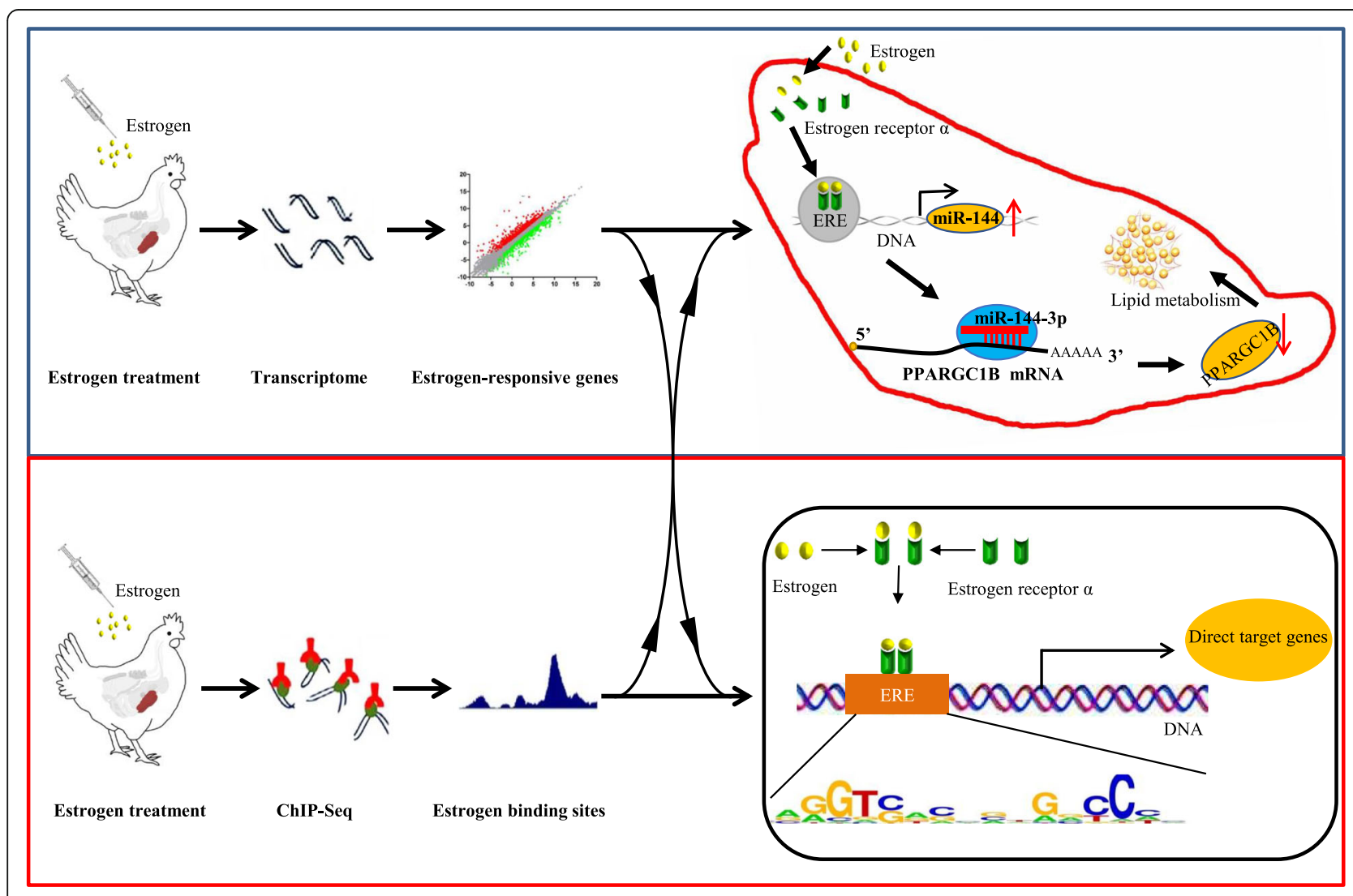

Fig. 7 Model of estrogen-mediated lipid metabolism by miR-144 and estrogen functional sites 
water. The corn soybean basal diets containing 15\% crude protein, $5 \%$ crude fat, $6 \%$ Crude Fiber, and 2750 $\mathrm{kcal} / \mathrm{kg}$ energy were obtained from Shandong Newhope Liuhe Group Co., Ltd. (Liuhe, Shandong, China). A total of 30 chickens with similar body weight $(680 \pm 24.6 \mathrm{~g})$ at 10 weeks of age were selected and subdivided randomly into four groups. Three groups $(n=8)$ were injected intramuscularly with $17 \beta$-estradiol (dissolved in olive oil) (Sigma, St. Louis, MO, USA) at $0.5,2.0$ or $8.0 \mathrm{mg} / \mathrm{kg}$ of body weight. One group $(n=6)$ serving as a control was given vehicle (olive oil) only. All chickens were euthanized by cervical dislocation at $12 \mathrm{~h}$ after treatment. A portion of the fresh liver tissue was embedded with optimum cutting temperature compound for oil red $\mathrm{O}$ staining. The rest of the liver was snap-frozen in liquid nitrogen and stored at $-80^{\circ} \mathrm{C}$ in a freezer until use. Three livers from the control group and three livers from the $8.0 \mathrm{mg} / \mathrm{kg} 17 \beta$-estradiol group were subjected to RNA-Seq. Livers from the $8.0 \mathrm{mg} / \mathrm{kg} 17 \beta$-estradiol group were also used for ChIP-Seq.

Primary hepatocytes culture and estrogen administration The isolation, purification, and culture of chicken primary hepatocytes were performed as described previously $[19,42]$. The chicken hepatocytes were isolated from 18-day chicken embryonic livers. Cells were divided into four groups with triplicates. The cells were starved for $6 \mathrm{~h}$ after they grew to $80 \%$ confluence. Then, we added $17 \beta$-estradiol dissolved in $0.1 \%$ ethanol to final concentrations of $25 \mathrm{nM}, 50 \mathrm{nM}$, or $100 \mathrm{nM}$. Cells treated with ethanol only were used as controls. After $12 \mathrm{~h}$ incubation, cells were collected and stored at $80^{\circ} \mathrm{C}$ until use.

\section{Oil red 0 staining}

The optimum cutting temperature compoundembedded liver tissue sample was sectioned with a freezing microtome. The sections were washed with PBS, fixed with $4 \%$ paraformaldehyde for $30 \mathrm{~min}$ at room temperature and then stained with $0.2 \%$ oil red $\mathrm{O}$ solution (Sigma) for $15 \mathrm{~min}$. After staining, sections were washed with PBS and counterstained with hematoxylin for $5 \mathrm{~min}$. The washed sections were observed under a microscope at $200 \times$ and $400 \times$ magnifications.

\section{RNA-Seq}

Total RNA was extracted from the chicken liver tissues using the TRIzol $^{\circ}$ reagent following manufacturer instructions (Invitrogen, Carlsbad, CA, USA). Libraries were constructed using the TruSeq Stranded Total RNA LT (with Ribo-Zero ${ }^{\text {Tx }}$ Gold) Set B (cat. \# RS-122-2302; Illumina, San Diego, CA, USA). The libraries were sequenced on the Illumina HiSeq 4000 platform via the $150 \mathrm{bp}$ pair-end sequencing strategy following manufacturer instructions. The obtained raw reads were cleaned using the FASTX-Toolkit (http://hannonlab. cshl.edu/fastx_toolkit/index.html). FASTQ files of clean paired-end reads were aligned to the reference genome using TopHat. The reference genome for the chicken (Gallus 5.0) was downloaded from the UCSC Genome Browser. The transcript abundance and putative novel mRNA isoforms were analyzed in the Cufflinks software. Next, the FPKM values were used to quantify the gene expression levels. In this study, the FDR was used to determine the threshold of the $p$ value in multiple tests and analyses.

After annotation, the unannotated transcripts were employed to identify lncRNAs. We applied the following filtering criteria: (1) exon number $\geq 2$; (2) transcript length $\geq 200 \mathrm{bp}$; (3) predicted open reading frame $<300$ bp; (4) the transcript aligned to Pfam [43] without significant hits; (5) coding-noncoding index score $<0$ [44]; and (6) coding potential calculator score $<0$ [45].

\section{miRNA-Seq}

Small RNA was extracted from chicken liver tissue samples using the mirVana ${ }^{\text {Tu }}$ miRNA Isolation Kit (cat. \# AM1561, Ambion, Austin, TX, USA). The extracted RNA samples were ligated sequentially with $3^{\prime}$ and $5^{\prime}$ RNA adapters by means of T4 RNA ligase (cat. \# M02421; BioLabs, Beverly, MA, USA). The ligated RNA samples were reverse-transcribed and amplified by PCR to generate cDNAs. The cDNAs of appropriate lengths were purified from an agarose gel to construct sequence libraries. After purification, the small-RNA libraries were quantified on a Qubit Fluorometer (Invitrogen) and used for cluster generation and $50 \mathrm{bp}$ single-end sequencing analysis with an Illumina HiSeq 2000 system.

An initial filtering step was performed using the Fastxtoolkit to remove adaptor sequences, low-quality reads (base quality less than 10), and short reads (shorter than $18 \mathrm{nt}$ ) before the clean reads were collected and subjected to bioinformatics analysis. Clean reads were first compared with the miRBase database 21.0 using the CLC Genomics Workbench 5.5 commercial software (CLC Bio, Aarhus, Denmark) to identify known miRNAs. The unmatched sequences were screened against the noncoding RNA database, Rfam, and piRNA database to filter out rRNAs, tRNAs, snRNAs, and snoRNAs. After the elimination of repeat-associated small RNAs, degradation fragments of mRNAs, and known miRNAs, the remaining reads were mapped to the chicken genome using Burrows-Wheeler Alignment to obtain pre-miRNA sequences [46]. The mapped sequences were then utilized to predict novel miRNAs by means of MIREAP. The expression of the identified miRNAs was normalized by calculation of TPM. The differential significance was identified using EdgeR software with the 
following thresholds: FDR $<0.05$ and fold change $\geq 1.5$ or fold change $\leq 0.667$.

\section{ChIP-Seq}

The ChIP assay was performed as described previously [19]. In brief, fresh liver tissue samples collected from chickens treated with $17 \beta$-estradiol were cross-linked with $1 \%$ formaldehyde, after which the cross-linking was stopped by the addition of $2.0 \mathrm{M}$ glycine. Isolated DNA was fragmented and incubated with a monoclonal specific ER $\alpha$ antibody $(0.2 \mathrm{mg} / \mathrm{mL}$, cat. \# MA5-13065; Invitrogen) or IgG antibody (Cell Signaling Technology, Danvers, MA, USA). The immunoprecipitated DNA fragments were quantified and used to construct the DNA libraries using the ChIP-Seq Sample Prep Kit (Illumina). The libraries were then sequenced on the Illumina HiSeq 2500 platform using 50 bp single-end sequencing analysis. Raw reads were subjected to a quality check and trimming, after which the obtained clean reads were aligned to the chicken genome (Gallus 5.0) via Burrows-Wheeler Alignment. Peak calling procedures were performed in MACS2 [47] with threshold $p$ values $\leq 0.005$. To perform a motif search, all positive peaks were used, and the peak sequences were extended on both sides to obtain a 500 bp sequence. The extended $500 \mathrm{bp}$ sequences were then used to discover motifs using MEME and FIMO. MAST was employed for motif alignment to exclude duplicate motifs, whereas Tomtom was used for annotation of the discovered motifs.

\section{Functional enrichment}

GO and Kyoto Encyclopedia of KEGG pathway enrichment analyses of genes were performed by DAVID. $p$ value $<0.05$ was used as the cut-off criterion for GO and KEGG pathway enrichment analyses.

\section{miRNA target gene prediction}

The miRNA target prediction software programs miRDB, TargetScan 7.1 and PicTar were used to predict miRNA target genes. Only when miRNA-mRNA pairs were positively predicted by $>2$ of these software programs were the pairs taken as a positive result.

\section{Luciferase assays}

A target fragment was amplified by PCR with special primers containing XhoI and NotI restriction sites. Seven bases of binding sites in 3'UTR were deleted to create a mutant version by means of special primers designed for overlap extension PCR. Then, the PCR product was cloned into the XhoI-and-NotI doubledigested psi-CHECK ${ }^{\mathrm{Tw}}-2$ plasmid (Promega, Madison, WI, USA) by means of T4 ligase (Biolabs, Beverly, MA, USA). All of the constructed vectors were confirmed by PCR and sequencing (BGI, Shenzhen, China). A chicken embryonic fibroblast cell line (DF1) was cultured and cotransfected with the constructed luciferase vector and a miRNA mimic or mimic negative control (mimic NC) with Lipofectamine ${ }^{\text {Tw }} 2000$ (Thermo, Waltham, MA, USA). The cell lysates were harvested $48 \mathrm{~h}$ after transfection. The Renilla luciferase and firefly luciferase activities were measured using a Dual Luciferase Reporter Assay System (Promega). For each transfected group, the procedure was performed in triplicate in at least three independent experiments.

\section{Quantitative real-time PCR (qRT-PCR)}

The expression levels of some selected mRNAs and lncRNAs were validated by qRT-PCR. The PrimeScript ${ }^{\mathrm{tm}}$ RT Reagent kit with gDNA Eraser (TaKaRa, Dalian, China) was used to synthesize the cDNA according to manufacturer instructions. The qRT-PCR was performed using the SYBR Green method in a LightCycler 96 instrument. Each reaction contained $5 \mu \mathrm{L}$ of SYBR Green PCR Master Mix (TaKaRa), 3.5 $\mu \mathrm{L}$ of RNase-free water, $0.5 \mu \mathrm{L}$ each of forward and reverse primers, and $0.5 \mu \mathrm{L}$ of extracted cDNA. The reactions were amplified using the following conditions: denaturation at $95^{\circ} \mathrm{C}$ for 5 min; followed by 40 PCR cycles at $95^{\circ} \mathrm{C}$ for $30 \mathrm{~s}, 60^{\circ} \mathrm{C}$ for $30 \mathrm{~s}$, and $72{ }^{\circ} \mathrm{C}$ for $20 \mathrm{~s}$; and then a further 10 -min extension at $72{ }^{\circ} \mathrm{C}$. All reactions were performed in triplicate. The expression levels were measured in terms of the cycle threshold $(\mathrm{Ct})$ and then normalized to the expression of $\beta$-actin using the $2^{-\Delta \Delta C t}$ method. The primers used were designed using the NCBI PrimerBLAST tool and synthesized by Sangon Biotech (Shanghai, China). All primer sequences are listed in Table S6.

Expression of the miRNA was detected by stem-loop qRT-PCR. Reverse transcription of miRNAs was performed using miRNA-specific stem-loop primers and the PrimeScript RT Reagent Kit (TaKaRa). The primers used for reverse transcription and qRT-PCR were designed and purchased from GenePharma Co., Ltd. (Shanghai, China). The miRNA expression levels were normalized to the expression of U6, and the other protocols were the same as described above.

\section{ChIP-quantitative PCR (ChIP-qPCR) analysis}

The immunoprecipitated DNA fragments were also used to verify the interaction of ER $\alpha$ and selected binding sites by ChIP-qPCR. Meanwhile, 20\% of starting chromatin without chromatin immunoprecipitation served as input to represent the unselected DNA content. The fold enrichment method was chosen to normalize the ChIP-qPCR data: Fold enrichment $=$ $\log _{2}{ }^{-\Delta \Delta \mathrm{Ct}}, \Delta \mathrm{Ct}=\mathrm{Ct}$ (IP) $-\mathrm{Ct}$ (Input) $-\log _{2}{ }^{5}, \Delta \Delta \mathrm{Ct}=\Delta \mathrm{Ct}$ $-\Delta \mathrm{Ct}$ (IgG). Gene-specific primers for the putative binding-site regions were designed using the NCBI Primer-BLAST tool and synthesized by Sangon Biotech 
(Shanghai, China). All ChIP-qPCR primer sequences used are listed in Table S7.

\section{Statistical analyses}

Statistical analyses were carried out using SPSS version 20.0 (IBM, Chicago, IL, USA). One-way ANOVA were used for statistical analysis, followed by Dunnett's test. The results were presented as Mean \pm SEM of more than 6 replicates, $p<0.05$ was considered statistically significant.

\begin{abstract}
Abbreviations
VLDL: Very low-density lipoprotein; ERs: Estrogen receptors; EREs: Estrogen response elements; DE: Differentially expressed; 3'UTRs: 3'-untranslated regions; miRNAs: microRNAs; IncRNAs: Long noncoding RNAs; FPKM: Fragment per kilobase of exon model per million mapped reads; FDR: False discovery rate; TPM: Transcripts per million clean reads; GO: Gene Ontology; KEGG: Kyoto Encyclopedia of Genes and Genomes; DF1: Fibroblast cell line; qRT-PCR: Quantitative real-time PCR; Ct: Cycle threshold; ChIPqPCR: ChIP-quantitative PCR; APOB: Apolipoprotein B; APOV1: Apovitellenin 1; TG: Triglyceride; TSSs: Transcription start sites
\end{abstract}

\section{Supplementary Information}

The online version contains supplementary material available at https://doi. org/10.1186/s12864-021-07679-y.

Additional file 1: Table S1. Descriptive summary of data generated by RNA-seq.

Additional file 2: Table S2. List of estrogen-responsive genes.

Additional file 3: Table S3. Descriptive summary of data generated by miRNA-seq.

Additional file 4: Table S4. Descriptive summary of data generated by ChIP-seq.

Additional file 5: Table S5. List of genes directly targeted by estrogen.

Additional file 6: Table S6. $q R T-P C R$ primers.

Additional file 7: Table S7. ChIP-qPCR primers.

\section{Acknowledgements}

Not applicable.

\section{Authors' contributions}

RJ performed the experiments and wrote the manuscript. TW, JK, WZ and WD participated in management of the experimental animals and the sample collection. LZ and LH contributed to the GRT-PCR analyses. YF, WY, OK, WH, TY and KX participated in the experiment design and critical discussion. LX conceived the study and provided overall supervision. All authors read and approved the final manuscript.

\section{Funding}

This research was funded by the National Natural Science Foundation of China-Henan Joint fund, grant number U1704233; Henan International Cooperative Research Project, grant number 162102410030; Innovation Research Team of Ministry of Education, grant number IRT-16R23 and Key Science and Technology Research Project of Henan Province, grant number 151100110800. The funders had no role in study design, data collection and analysis, decision to publish, or preparation of the manuscript.

\section{Availability of data and materials}

All data generated in this manuscript have been deposited in NCB Sequence Read Archive under the accession number PRJNA434773.

\section{Declarations}

Ethics approval and consent to participate

The experiments and animal care were performed in accordance with the protocol approved by the Regulations for the Administration of Affairs Concerning Experimental Animals (Ministry of Science and Technology, China, 2004). The protocol was approved by the Institutional Animal Care and Use Committee (IACUC) of Henan Agricultural University, Zhengzhou, P.R. China (Permit Number: 17-0118).

\section{Consent for publication}

Not applicable.

\section{Competing interests}

The authors declare that they have no competing interests.

\section{Author details}

${ }^{1}$ College of Animal Science and Veterinary Medicine, Henan Agricultural University, Zhengzhou 450002, China. ${ }^{2}$ Henan Innovative Engineering Research Center of Poultry Germplasm Resource, Henan Agricultural University, Zhengzhou 450002, China. ${ }^{3}$ International Joint Research Laboratory for Poultry Breeding of Henan, Henan Agricultural University, Zhengzhou 450002, China. ${ }^{4}$ College of Pharmacy, National and Local Joint Engineering Research Center of Targeted and Innovative Therapeutics, Chongqing Key Laboratory of Kinase Modulators as Innovative Medicine, Chongqing University of Arts and Sciences, Chongqing, China. ${ }^{5}$ Center for Cellular Therapy, Medical University of South Carolina, Charleston, SC 29425, USA.

Received: 31 August 2020 Accepted: 5 May 2021

Published online: 09 June 2021

\section{References}

1. Anderson VE, Hammes GG. Distribution of reaction intermediates on chicken liver fatty acid synthase. Biochemistry. 1985;24(9):2147-54. https:// doi.org/10.1021/bi00330a007.

2. Leveille GA, O'Hea EK, Chakbabarty K. In vivo lipogenesis in the domestic chicken. Proc Soc Exp Biol Med. 1968;128(2):398-401. https://doi.org/10.31 81/00379727-128-33022.

3. O'Hea EK, Leveille GA. Lipid biosynthesis and transport in the domestic chick (Gallus domesticus). Comp Biochem Physiol. 1969;30(1):149-59. https://doi.org/10.1016/0010-406X(69)91309-7.

4. Mahon MG. Multiple Involvement of Clusterin in chicken ovarian follicle development. Binding to two oocyte-specific members of the low density lipoprotein receptor gene family. J Biol Chem. 1999;274(7):4036-44. https:// doi.org/10.1074/jbc.274.7.4036.

5. Li H, Ma Z, Jia L, Li Y, Xu C, Wang T, et al. Systematic analysis of the regulatory functions of microRNAs in chicken hepatic lipid metabolism. Sci Rep. 2016;6(1):31766. https://doi.org/10.1038/srep31766.

6. Li H, Wang T, Xu C, Wang D, Ren J, Li Y, et al. Transcriptome profile of liver at different physiological stages reveals potential mode for lipid metabolism in laying hens. BMC Genomics. 2015;16(1):763. https://doi.org/10.1186/s12 864-015-1943-0.

7. Tanabe $\mathrm{Y}$, Nakamura T, Tanase H, Doi O. Comparisons of plasma LH, progesterone, testosterone and estradiol concentrations in male and female chickens (Gallus domesticus) from 28 to 1141 days of age. Endocrinol Jpn. 1981;28(5):605-13. https://doi.org/10.1507/endocrj1954.28.605.

8. Williams J, Harvey S. Plasma concentrations of luteinizing hormone growth hormone, oestradiol, testosterone and androstenedione in the domestic hen from 6 weeks of age to sexual maturity. Reprod Nutr Dev. 1986;26(2A): 515-22. https://doi.org/10.1051/rnd:19860311.

9. Paech K, Webb P, Kuiper GGJM, Nilsson S, Gustafsson J, Kushner PJ, et al. Differential ligand activation of estrogen receptors ERa and ER $\beta$ at AP1 sites. Science. 2015:277(5331):1508-10.

10. Kumar $V$, Chambon $P$. The estrogen receptor binds tightly to its responsive element as a ligand-induced homodimer. Cell. 1988;55(1):145-56. https:// doi.org/10.1016/0092-8674(88)90017-7.

11. Khan S, Abdelrahim M, Samudio I, Safe S. Estrogen receptor/Sp1 complexes are required for induction of cad gene expression by $17 \beta$-estradiol in breast cancer cells. Endocrinology. 2003;144(6):2325-35. https://doi.org/10.1210/ en.2002-0149. 
12. Kushner PJ, Agard DA, Greene GL, Scanlan TS, Shiau AK, Uht RM, et al. Estrogen receptor pathways to AP-1. J Steroid Biochem Mol Biol. 2000;74(5): 311-7. https://doi.org/10.1016/S0960-0760(00)00108-4.

13. Madeo A, Maggiolini M. Nuclear alternate estrogen receptor GPR30 mediates 17?-estradiol-induced gene expression and migration in breast Cancer-associated fibroblasts. J Cancer Res. 2010;70(14):6036-46. https://doi. org/10.1158/0008-5472.CAN-10-0408.

14. Tang Z, Zhang R, Lian Z, Deng S, Yu K. Estrogen-receptor expression and function in female reproductive disease. Cells. 2019;8(10):1123. https://doi. org/10.3390/cells8101123.

15. Carroll JS, Liu XS, Brodsky AS, Li W, Meyer CA, Szary AJ, et al. Chromosomewide mapping of estrogen receptor binding reveals long-range regulation requiring the Forkhead protein FoxA1. Cell. 2005;122(1):33-43. https://doi. org/10.1016/j.cell.2005.05.008.

16. Carroll JS, Meyer CA, Song J, Li W, Geistlinger TR, Eeckhoute J, et al. Genome-wide analysis of estrogen receptor binding sites. Nat Genet. 2006; 38(11):1289-97. https://doi.org/10.1038/ng1901.

17. Walzem RL, Hansen RJ, Williams DL, Hamilton RL. Estrogen induction of VLDLy assembly in egg-laying hens. J Nutr. 1999;129(2S Suppl):467S-72S. https://doi.org/10.1093/jn/129.2.4675.

18. Berkowitz EA, Chu WW, Evans MI. Insulin inhibits the estrogen-dependent expression of the chicken very low density apolipoprotein II gene in Leghorn male hepatoma cells. Mol Endocrinol. 1993;7(4):507-14. https://doi. org/10.1210/mend.7.4.8502236.

19. Ren J, Xu N, Zheng H, Tian W, Li H, Li Z, et al. Expression of thyroid hormone responsive SPOT 14 gene is regulated by estrogen in chicken (Gallus gallus). Sci Rep. 2017;7(1):10243. https://doi.org/10.1038/s41598-017-08452-6.

20. Wirtenberger M, Tchatchou S, Hemminki K, Schmutzhard J, Sutter C, Schmutzler RK, et al. Associations of genetic variants in the estrogen receptor coactivators PPARGC1A, PPARGC1B and EP300 with familial breast cancer. Carcinogenesis. 2006;27(11):2201-8. https://doi.org/10.1093/carcin/bgl067.

21. Leigh $G$, Noemi R, Alberto CD, Aranda JF, Ramírez CM, Elisa A, et al. Identification of miR-148a as a novel regulator of cholesterol metabolism. Nat Med. 2015;21(11):1280-9.

22. Cheng L, Zhu Y, Han H, Zhang Q, Cui K, Shen H, et al. MicroRNA-148a deficiency promotes hepatic lipid metabolism and hepatocarcinogenesis in mice. Cell Death Dis. 2017;8(7):e2916. https://doi.org/10.1038/cddis.2017.309.

23. Gerin I, Clerbaux LA, Haumont O, Lanthier N, Das AK, Burant CF, et al. Expression of miR-33 from an SREBP2 intron inhibits cholesterol export and fatty acid oxidation. J Biol Chem. 2010;285(44):33652-61. https://doi.org/10.1 074/jbc.M110.152090.

24. Tan Y, Gan M, Fan Y, Li L, Zhong Z, Li X, et al. miR-10b-5p regulates 3T3-L1 cells differentiation by targeting Apol6. Gene. 2019;687:39-46. https://doi. org/10.1016/j.gene.2018.11.028.

25. Chen Z, Qiu H, Ma L, Luo J, Sun S, Kang K, et al. miR-30e-5p and miR-15a Synergistically Regulate Fatty Acid Metabolism in Goat Mammary Epithelial Cells via LRP6 and YAP1. Int J Mol Sci. 2016;17(11):1909.

26. Matthews J, Gustafsson JA. Estrogen signaling: a subtle balance between ER alpha and ER beta. Mol Interv. 2003;3(5):281-92. https://doi.org/10.1124/mi.3.5.281.

27. Lin CY, Vega VB, Thomsen JS, Zhang T, Kong SL, Xie M, et al. Wholegenome cartography of estrogen receptor alpha binding sites. PLoS Genet. 2007;3(6):e87. https://doi.org/10.1371/journal.pgen.0030087.

28. Mason CE, Shu FJ, Wang C, Session RM, Kallen RG, Sidell N, et al. Location analysis for the estrogen receptor-alpha reveals binding to diverse ERE sequences and widespread binding within repetitive DNA elements. Nucleic Acids Res. 2010;38(7):2355-68. https://doi.org/10.1093/nar/gkp1188.

29. Ijichi N, Ikeda K, Horie-Inoue K, Inoue S. FOXP1 and estrogen signaling in breast cancer. Vitam Horm. 2013;93:203-12. https://doi.org/10.1016/B978 0-12-416673-8.00006-X.

30. Hurtado A, Holmes KA, Rossinnes CS, Schmidt D, Carroll JS. FOXA1 is a key determinant of estrogen receptor function and endocrine response. Nat Genet. 2011;43(1):27-33. https://doi.org/10.1038/ng.730.

31. Liu X, Zhang Y, Chen Y, Li M, Zhou F, Li K, et al. In situ Capture of chromatin interactions by Biotinylated dCas9. Cell. 2017;170(5):1028-43. https://doi. org/10.1016/j.cell.2017.08.003.

32. Ambros $V$. The function of animal MicroRNAs. Nature. 2004:431(7006):350-5. https://doi.org/10.1038/nature02871.

33. Mercer TR, Dinger ME, Mattick JS. Long non-coding RNAs: insights into functions. Nat Rev Genet. 2009;10(3):155-9. https://doi.org/10.1038/nrg2521.

34. Mccarty CM, Risner G, Waikel RL. Estrogen mediated miRNA expression profiles during Cardiomyocyte hypertrophy. FASEB J. 2011;25(1):509.
35. Kovalchuk O, Tryndyak VP, Montgomery B, Boyko A, Kutanzi K, Zemp F, et al. Estrogen-induced rat breast carcinogenesis is characterized by alterations in DNA methylation, histone modifications and aberrant microRNA expression. Cell Cycle. 2007;6(16):2010-8. https://doi.org/10.4161/cc.6.16.4549.

36. Niknafs YS, Han S, Ma T, Speers C, Zhang C, Wilder-Romans K, et al. The IncRNA landscape of breast cancer reveals a role for DSCAM-AS1 in breast cancer progression. Nat Commun. 2016;7(1):12791. https://doi.org/10.1038/ ncomms 12791.

37. Lim LP, Lau NC, Garrett-Engele P, Grimson A, Schelter JM, Castle J, et al. Microarray analysis shows that some microRNAs downregulate large numbers of target mRNAs. Nature. 2005;433(7027):769-73. https://doi.org/1 0.1038/nature03315

38. Fujita Y, Kojima K, Ohhashi R, Hamada N, Nozawa Y, Kitamoto A, et al. MiR148a attenuates paclitaxel resistance of hormone-refractory, drug-resistant prostate cancer PC3 cells by regulating MSK1 expression. J Biol Chem. 2010; 285(25):19076-84. https://doi.org/10.1074/jbc.M109.079525.

39. Guo SL, Peng Z, Yang X, Fan KJ, Ye H, Li ZH, et al. miR-148a promoted cell proliferation by targeting p27 in gastric cancer cells. Int J Biol Sci. 2011;7(5): 567-74. https://doi.org/10.7150/ijbs.7.567.

40. Vivacqua A, De Marco P, Santolla MF, Cirillo F, Pellegrino M, Panno ML, et al. Estrogenic gper signaling regulates mir144 expression in cancer cells and cancer-associated fibroblasts (cafs). Oncotarget. 2015;6(18):16573-87. https:// doi.org/10.18632/oncotarget.4117.

41. Zhang DD, Wang DD, Wang Z, Wang YB, Li GX, Sun GR, et al. Estrogen Abolishes the Repression Role of gga-miR-221-5p Targeting ELOVL6 and SQLE to Promote Lipid Synthesis in Chicken Liver. Int J Mol Sci. 2020;21(5): 1624.

42. Ren J, Li Y, Xu N, Li H, Li C, Han R, et al. Association of estradiol on expression of melanocortin receptors and their accessory proteins in the liver of chicken (Gallus gallus). Gen Comp Endocrinol. 2017;240:182-90. https://doi.org/10.1016/j.ygcen.2016.10.012.

43. Sun L, Zhang Z, Bailey TL, Perkins AC, Tallack MR, Xu Z, et al. Prediction of novel long non-coding RNAs based on RNA-Seq data of mouse Klf1 knockout study. BMC Bioinformatics. 2012;13(1):331. https://doi.org/10.11 86/1471-2105-13-331.

44. Kong L, Zhang $Y$, Ye ZQ, Liu XQ, Zhao SQ, Wei L, et al. CPC: assess the protein-coding potential of transcripts using sequence features and support vector machine. Nucleic Acids Res. 2007;35(Web Server issue):W345-9.

45. Liang $\mathrm{S}$, Luo H, Bu D, Zhao G, Yu K, Zhang C, et al. Utilizing sequence intrinsic composition to classify protein-coding and long non-coding transcripts. Nucleic Acids Res. 2013;41(17):e166.

46. Li H, Durbin R. Fast and accurate short read alignment with burrowswheeler transform. Bioinformatics. 2009;25(14):1754-60. https://doi.org/10.1 093/bioinformatics/btp324.

47. Zhang G, Cai L, Li Q, Bo L, Larkin DM, Lee C, et al. Comparative genomics reveals insights into avian genome evolution and adaptation. Science. 2014 346(6215):1311-20. https://doi.org/10.1126/science.1251385.

\section{Publisher's Note}

Springer Nature remains neutral with regard to jurisdictional claims in published maps and institutional affiliations.

Ready to submit your research? Choose BMC and benefit from:

- fast, convenient online submission

- thorough peer review by experienced researchers in your field

- rapid publication on acceptance

- support for research data, including large and complex data types

- gold Open Access which fosters wider collaboration and increased citations

- maximum visibility for your research: over $100 \mathrm{M}$ website views per year

At $\mathrm{BMC}$, research is always in progress.

Learn more biomedcentral.com/submission 